\title{
Visual Discrimination in Pigeons Impaired by Glutamatergic Blockade of Nucleus Accumbens
}

\author{
PASCUAL A. GARGIULO ${ }^{* 1}$ MARTINA SIEMANN* AND JUAN D. DELIUS $\dagger$ \\ *Laboratorio de Neurociencias y Psicología Experimental, Universidad Católica de Mendoza, and Unidad de la \\ Farmacología de la Conducta, Universidad Nacional de Cuyo, RA 5500 Mendoza, Argentina \\ $\dagger$ †Allgemeine Psychologie, Universität Konstanz, D 78434 Konstanz, Germany
}

\begin{abstract}
The nucleus accumbens septi (Acc) is thought to be involved in the control of cognitive processes and to be implicated in the pathophysiology of schizophrenia. Because perceptual-cognitive distortions are a core symptom in schizophrenia, any evidence that the Acc intervenes in a sensory recognition task in an animal species would be of interest. Pigeons were instrumentally trained to discriminate visual shapes. The acute effects of drug microinjections into the Acc on the discrimination of the training shapes, on the correction responding after errors, and on the generalisation to different shapes were examined. The effects of conduction blockade with lidocaine, glutamatergic blockade with 7-aminophosphonoheptanoic acid, and dopaminergic stimulation with apomorphine on behavioural performance were tested. No effects were observed with lidocaine and apomorphine. A significant and reversible performance disruption to near chance levels was obtained after aminophosphonoheptanoic acid injections into the Acc. It appears that a glutamatergic blockade of the Acc interferes with the visual discrimination processes of pigeons.
\end{abstract}

Nucleus accumbens Pigeons Visual discrimination Glutamatergic blockade Dopaminergic activation

THE nucleus accumbens septi (Acc) of the basal forebrain is a major component of the ventral striatum of mammals. Among other inputs, it receives a dopaminergic projection from the ventral tegmental area (19) and a glutamatergic projection from the limbic system (3). It appears that the Acc is involved in the control of several behavioural processes, some of them of a cognitive nature: locomotion (23), stereotypies (10), motivation (28), reward (2), learning (31), and memory (29). Both dopaminergic and glutamatergic mechanisms seem to intervene in at least some of these various Acc functions (30,33). The mammalian Acc has received much attention because of its involvement in the pathophysiology of human schizophrenia (11).

Birds possess a structure that appears to be anatomically homologous to the Acc of mammals. As depicted in the standard pigeon brain atlas (17), it is located below the ventral edge of the lateral forebrain ventricles in the septal area. However, according to some of the more recent data the avian Acc, in fact, extends more ventrally, laterally, and posteriorly than delineated in the atlas, surrounding the bed nucleus of the stria terminalis $(13,26,34)$. It receives a substantial, very probably dopaminergic input from the ventral mesencephalic tegmentum $(8,18)$. It also contains enkephalin (26) and vasoactive intestinal peptide receptors (15). The Acc projects back to the midbrain tegmentum through a gabaergic pathway (13). A glutamatergic innervation of the avian Acc has not yet been sought for, but it receives a corticostriatal-like projection (34). Nothing seems to be known about the function of the Acc in birds. The sophisticated cognitive competencies that pigeons can exhibit when discriminating visual stimuli $(9,32)$ suggest, however, that they may be suitable subjects in which to examine whether the Acc plays a role in perception and cognition. The present study accordingly explored whether a conduction blockade, a glutamatergic blockade, or a dopaminergic stimulation of the Acc would affect pigeons performing a complex conditioned visual discrimination and generalisation task.

\section{METHODS}

Subjects

Adult domestic pigeons (Columba livia) of local homing stock and weighing between 450 and $550 \mathrm{~g}$ were used. They were kept in individual $40-\times 45-\times 35-\mathrm{cm}$ stainless steel grid cages located in a well ventilated and illuminated $(12 \mathrm{~h} \mathrm{on} / 12 \mathrm{~h}$ off $)$ animal room. They were maintained at $80 \%$ of their normal weight throughout the experiment. All experimental treatments complied with the German animal protection laws and regulations.

\section{Apparatus}

Horizontal conditioning platforms (36) controlled by a Commodore PC were used. They were attached to the pigeons' home cages replacing their standard feeding troughs. Each platform incorporated two side-by-side transparent pecking keys (centres 5

\footnotetext{
${ }^{1}$ To whom reprint requests should be addressed. E-mail: gargiulo@fmed2.uncu.edu.ar
} 
$\mathrm{cm}$ apart, diameter $2.5 \mathrm{~cm}$ ). Separate light-emitting-diode matrices $(5 \times 7$ green diodes, $1.2 \times 1.7 \mathrm{~cm})$ served to present visual patterns under these keys. Two solenoid feeders could deliver rewards consisting of a few grains of millet onto the keys.

\section{Procedure}

The pigeons were first automatically shaped to peck the keys. This involved successive blocks of 40 trials. A trial began with a 20 -s pause. A small pentagonal stimulus was then presented for $8 \mathrm{~s}$ randomly under either the right or left key, the other key remaining dark. A peck to the illuminated key yielded an immediate reward on the corresponding key followed by a 2-s feeding time. However, if the animal did not peck, a reward was issued at the end of the stimulus presentation. As soon as $80 \%$ of the trials of a block had yielded pecks, these latter free rewards were discontinued; the animals receiving food only if they pecked the key during a now temporally unlimited presentation of the stimulus. When the subjects emitted 40 such instrumental responses, they entered into the training phase.

The daily training sessions consisted of 10 blocks of 40 trials each. A trial began with the simultaneous presentation of two discriminative stimuli under the keys. Two mirror-image visual stimuli were used, a p-like shape and a q-like shape (size: $3 \times 5$ diodes, $1 \times 1.2 \mathrm{~cm}$ ) in either a standard or an inverted (180-degree rotated) orientation. The two types of stimulus pairs and the right/left key allocation of the two stimuli of a pair were randomised across the successive trials of each block. The $p$ (or d) shape was defined as correct, the $\mathrm{q}$ (or b) shape as incorrect. Three pecks delivered to the key showing a correct stimulus yielded a reward accompanied by a 2 -s feeding time with darkened matrices. Three pecks made to the key displaying the incorrect stimulus yielded a penalty consisting of a 2-s time out with the matrix fully illuminated. A 2-s intertrial interval with dark matrices preceded the next trial. Trials ending in penalty were followed by a repeat trial with exactly the same stimulus configuration. This correction procedure ended when the correct stimulus was chosen. These correction trials were separately recorded but did not enter into the discrimination score calculations. When a criterion of $70 \%$ correct trials was satisfied within a block, the procedure changed. Now a random fifth of the trials were not reinforced, meaning that neither reward nor penalty was issued after response completion. The training phase ended when a criterion of $80 \%$ correct trials was achieved within a block of trials.

\section{Surgery}

When training was complete, pigeons were anaesthetised with an initial intramuscular (i.m.) dose of $0.1 \mathrm{~mL}$ of Kemint (Alvetra, ketamine chlorhydrate $100 \mathrm{mg} / \mathrm{mL}$ ) and $0.02 \mathrm{~mL}$ of Rompun (Bayer, xylazine $23 \mathrm{mg} / \mathrm{mL}$ ) per $100 \mathrm{~g}$ of b.w. The anaesthesia was maintained with additional $0.1 \mathrm{~mL}$ i.m. doses of Kemint given at 15-min intervals. While its head was held in a stereotaxic apparatus, each pigeon was implanted with two guide cannulae (stainless steel tubing, 23 gauge, $13 \mathrm{~mm}$ long) with their bevelled tips aimed at locations $2 \mathrm{~mm}$ above the right and left Acc. These latter structures were considered to be centred around the coordinates A 8.5, D 7.5, R and L 2.0 of the Karten and Hodos (17) pigeon brain atlas. The cannulae were fixed to the skull with acrylic cement and were kept occluded with removable stainless steel pins (30 gauge, $13 \mathrm{~mm}$ long). After surgery, the pigeons were allowed a week to recover before testing began.

\section{Testing}

It involved two consecutive daily sessions, an untreated baseline session and a drug or saline treatment session, each consisting of 3 blocks of 40 trials. Each of the blocks included 32 reinforced training pairs, as described earlier, and 8 interspersed, unreinforced generalisation trials. During these generalisation trials, the $\mathrm{p}$ (or d) and the $\mathrm{q}$ (or $\mathrm{b}$ ) shapes were again randomly assigned to the two keys, but they were presented with an horizontal, recumbent alignment, that is 90 degrees rotated with respect to the vertically aligned presentation used in training trials.

Between different drugs there was an interval of at least a 2 days. Immediately before a drug or saline testing session, the animals were injected intracerebrally. They were held manually and the occlusion pin of the relevant cannula was removed. A 30-gauge, 15-mm-long, stainless steel injection cannula (sized to reach the Acc), attached to a microsyringe (Hamilton), was introduced through the guide cannula. Volumes of $1 \mu \mathrm{L}$ of solution were gradually injected over 2 -min periods into both the left and right hemisphere sites. The injection cannula was left in place for additional 1-min periods to allow for diffusion. The following drugs were employed: lidocaine chlorhydrate (Research Biochemicals; Lid, $20 \mu \mathrm{g} / \mu \mathrm{L} ; 0.9 \mu \mathrm{g} / \mu \mathrm{L}$ sodium chloride vehicle), 7-aminophosphonoheptanoic acid (Research Biochemicals; AP-7, 3 or 1 $\mu \mathrm{g} / \mu \mathrm{L} ; 0.9 \mu \mathrm{g} / \mu \mathrm{L}$ sodium chloride vehicle), saline (Sal, 0.9 $\mu \mathrm{g} / \mu \mathrm{L}$ sodium chloride) and apomorphine (Teclapharm; Apo 1 with $10 \mu \mathrm{g} / \mu \mathrm{L}$; sodium bisulfide 0.1 or $1 \mu \mathrm{g} / \mu \mathrm{L}$, methyl-4hydroxybenzoate 0.12 and $1.2 \mu \mathrm{g} / \mu \mathrm{L}$ as stabilisers). As will be described later, not all pigeons were exposed to all the treatments listed.

\section{Histology}

After testing was complete, the birds were anaesthetised and injected intracerebrally with India ink, $1 \mu \mathrm{L}$ each side, using the same procedure described above. They were then transcardially perfused with saline and $10 \%$ formaline solution. The brains were removed from the skull and postfixed in the same formaline solution. Before sectioning they were placed into a $30 \%$ saccharose solution for at least 1 day. The brains were then mounted and frozen in a cryotome and cut at $40-\mu \mathrm{m}$ intervals. The block face was inspected with a $10 \times$ magnifying lens and every 5 th section around the injection site was mounted. Microscopic inspection of these sections ascertained the site locations. These locations were transferred to standard sections taken from a pigeon brain atlas (17).

\section{Data}

The relevant data were the percentage correct trials for training trials, the mean number of correction trials after an incorrect trial (total correction trials divided by total error trials), and the percent correct trials (to be defined below) during the generalisation tests obtained during the various baseline and the drug session. These scores are reported as means \pm SE. Nonparametric Wilcoxon tests were used throughout to assess statistical differences in performance between pairs of sessions.

\section{RESULTS}

\section{Histology}

Of the pigeons that were successfully trained, cannulated, and tested, five had their injection sites (small lesion, ink deposits) bilaterally located in the Acc or its immediate vicinity (Fig. 1) whereas in three pigeons at least one of the injection sites lay outside the Acc, in three instances within the overlying lateral ventricle (ink deposits on the ventricular ependyma). 


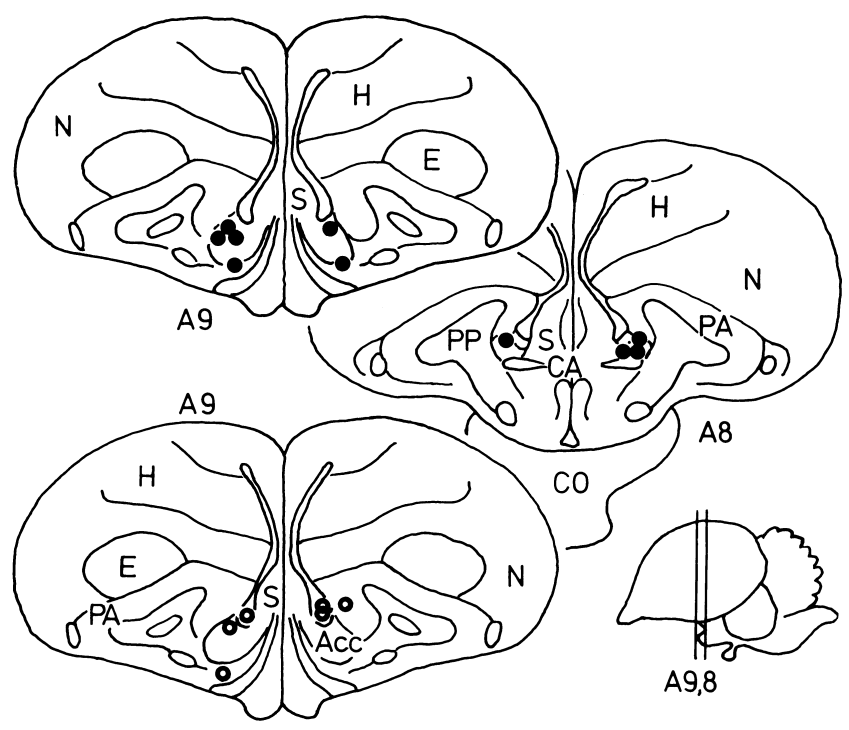

FIG. 1. Frontal brain sections showing the location of the injection sites. Filled circles mark the injection sites of 5 pigeons (pigeons $1,3,4,6$, and 8) where both right and left sites were within the Acc or its immediate neighbourhood. Open circles mark the injection sites of 3 pigeons (pigeons 2, 5, and 7) where at least one site was outside the Acc (ventricle or otherwise). Abbreviations: Acc, nucleus accumbens; CA, comissura anterior; $\mathrm{CO}$, chiasma opticum; $\mathrm{E}$, ectostriatum; $\mathrm{H}$, hyperstriatum; $\mathrm{N}$, neostriatum; PA, paleostriatum augmentatum; PP, paleostriatum primitivum; S, septum. A8 and A9 refers to stereotaxic planes (17).

\section{General}

The 8 pigeons needed between 11 and 52 (median 22) blocks of discrimination training to reach the $80 \%$ criterion. In the subsequent baseline sessions, they maintained an average accuracy of about $75 \%$ on the training component. The generalisation component of these same sessions yielded an unexpected result. The horizontal $\mathrm{q}$ (or b) shapes where consistently chosen more often than the horizontal p (or d) shapes. A detailed shape comparison revealed that the horizontal $\mathrm{q} / \mathrm{b}$ shapes shared more illuminated diode matrix locations with the rewarded vertical $\mathrm{p} / \mathrm{d}$ training shapes than did the horizontal $\mathrm{p} / \mathrm{d}$ shapes. Conversely, the horizontal $\mathrm{p} / \mathrm{d}$ shapes were more similar in the same way to the unrewarded vertical $\mathrm{q} / \mathrm{b}$ training shapes than were the horizontal $\mathrm{q} / \mathrm{b}$ shapes. The discrimination percentages for the gener-

TABLE 1

7-AMINOPHOSPHONOHEPTANOIC ACID (AP-7) TRANSITORILY AND SIGNIFICANTLY (*) DEPRESSED PERFORMANCE WHEN INJECTED BILATERALLY INTO THE NUCLEUS ACCUMBENS (ACC)

\begin{tabular}{lcccc}
\hline & Baseline & AP-7 & Baseline & Saline \\
\hline$\%$ training trials & $75.6 \pm 4.4$ & $58.7 \pm 4.1^{*}$ & $72.3 \pm 3.7$ & $79.1 \pm 4.1$ \\
$\begin{array}{c}\text { correct } \\
\text { Correction trials } \\
\text { per error }\end{array}$ & $1.5 \pm 0.2$ & $2.3 \pm 0.3^{*}$ & $1.4 \pm 0.2$ & $1.9 \pm 0.2$ \\
$\begin{array}{c}\% \text { generalisation } \\
\text { trials correct }\end{array}$ & $62.5 \pm 4.3$ & $50.0 \pm 5.6^{*}$ & $60.0 \pm 4.7$ & $62.5 \pm 2.2$ \\
\hline
\end{tabular}

The saline vehicle did not have any effect. Mean \pm SE of 5 pigeons.

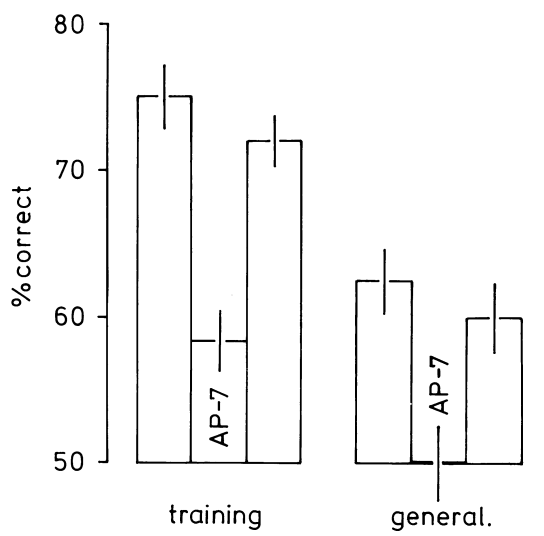

FIG. 2. Effects of 7-aminophosphonoheptanoic acid injected into the Acc on the discrimination and generalisation performance of pigeons. The columns represent the pre-baseline, AP-7 treatment and post-baseline sessions. Mean $\pm \mathrm{SE}$ of 5 pigeons.

alisation components were accordingly calculated with the choices of the horizontal $\mathrm{q} / \mathrm{b}$ shapes counted as correct, rather than incorrect as originally intended.

\section{7-Aminophosphonoheptanoic Acid}

Three pigeons (pigeons 1, 2, and 3) were first treated with $3-\mu \mathrm{g} / \mu \mathrm{L}$ AP-7 doses. These doses led to an arrest of activity so that no key responding occurred within the 60 -min period allowed. The same animals were retested with $1-\mu \mathrm{g} / \mu \mathrm{L}$ AP-7 doses after a 6-day interval and after they had again yielded average baseline performances. The remaining 5 pigeons (pigeons 4 to 8 ) were tested only with this lower dose. Neither motivational nor motor impairments were evident with this dose. The pigeons began to peck immediately and placed their pecks accurately. Furthermore the pigeons completed the corresponding sessions as swiftly as the baseline sessions. However, an appreciable discrimination and generalisation impairment was observed with bilateral injections of this AP-7 dose into the Acc (pigeons 1, 3, 4, 6, and 8; averages Table 1, Fig. 2). The average percentages of correct training pairs and correct generalisation pairs decreased significantly to close to $50 \%$ chance levels $(p<0.05$ against baselines). The correction trials per error were significantly increased ( $p<0.05$ against baselines). The same dose of AP-7 injected unilaterally into the Acc or nearby, but contralaterally, into the ventricle in 3 pigeons (pigeons 2, 5, and 7) had no significant effect on performance (Table 2). The tables also include the results of

TABLE 2

7-AMINOPHOSPHONOHEPTANOIC ACID (AP-7) HAD NO EFFECT WHEN NOT INJECTED BILATERALLY INTO THE NUCLEUS ACCUMBENS

\begin{tabular}{lccccc}
\hline & Baseline & AP-7 & Baseline & Saline \\
\hline$\%$ training trials & & & & & \\
$\begin{array}{c}\text { correct } \\
\text { correction trials }\end{array}$ & $77.0 \pm 7.0$ & $78.5 \pm 8.1$ & $79.8 \pm 3.9$ & $84.6 \pm 7.2$ \\
$\begin{array}{c}\text { per error } \\
\begin{array}{c}\text { generalisation } \\
\text { trials correct }\end{array}\end{array}$ & $1.6 \pm 0.6$ & $1.5 \pm 0.3$ & $1.9 \pm 0.5$ & $1.7 \pm 0.1$ \\
\hline
\end{tabular}

Mean \pm SE of 3 pigeons. 
TABLE 3

APOMORPHINE INJECTIONS INTO THE NUCLEUS ACCUMBENS DID NOT SIGNIFICANTLY AFFECT DISCRIMINATION OR GENERALISATION PERFORMANCE

\begin{tabular}{lrrr}
\hline & Baseline & Saline & Apomorphine \\
\hline \% training trials correct & $69.7 \pm 6.3$ & $79.1 \pm 7.2$ & $77.9 \pm 2.8$ \\
Correction trials per error & $1.5 \pm 0.3$ & $1.7 \pm 0.2$ & $1.7 \pm 0.2$ \\
$\%$ generalisation trials correct & $62.5 \pm 5.6$ & $62.5 \pm 2.2$ & $60.8 \pm 2.0$ \\
\hline
\end{tabular}

Mean \pm SE of 5 pigeons.

single baseline sessions run 3-6 days after the AP-7 sessions. The results of these sessions are statistically indistinguishable from those of the first baseline sessions. They document a full recovery of performance after the drug treatment, showing that the Acc-related AP-7 effect was not due to any permanent lesion-like effect (Table 1). The fact that the subsequent Sal treatment had no significant influence on any of the performance scores shows that the vehicle used was suitably neutral.

\section{Apomorphine}

The first three pigeons (pigeons 1 to 3 ) received $1-\mu \mathrm{g} / \mu \mathrm{L}$ Apo doses. The Apo effect was gauged against the same baseline sessions used for the Sal treatment mentioned above. Because this drug treatment yielded no effect, the dose was increased to 10 $\mu \mathrm{g} / \mu \mathrm{L}$ with the next 5 pigeons (pigeons 4 to 8 ). Three of these pigeons (pigeons 4, 5, and 8) also received separate baseline sessions immediately preceding the Apo treatment sessions. None of the Apo treatments had a significant effect on the discrimination and generalisation performance, regardless of whether the drug was injected into the Acc (Table 3) or elsewhere.

\section{Lidocaine}

Lid $(20 \mu \mathrm{g} / \mu \mathrm{L})$ did not yield any appreciable performance differences between baseline and treatment sessions regardless of whether the injections were into the Acc (pigeons 1, 3, and 4) or elsewhere (pigeons 2 and 5). A likely reason for this result is that the Lid is too short-acting an anaesthetic to sufficiently affect the performance across a whole treatment session.

\section{DISCUSSION}

Only AP-7 injections bilaterally into the Acc or its vicinity had a clear-cut and significant, but transitory detrimental effect on the discriminatory performance of pigeons. This treatment led to nearly chance choice levels with both the reinforced training and unreinforced generalisation pairs of stimuli (Table 1, Fig. 2). The increase in the number of correction trials per error may be a further sign of the same impairment but could also represent a stereotyped choice persistence (27). Since in mammals AP-7 is known to be a $N$-methyl-Daspartic acid-type glutamate receptor blocker (24) having a specific effect on the Acc functioning of rats (30), it seems very probable that the Acc of pigeons, like that of mammals, includes glutamatergic synapses. Since the effective dose of $1 \mu \mathrm{g} / \mu \mathrm{L}$ did not interfere with the mere execution of the instrumental task we may assume that the blocking affected a more specific process than simply motivational drive or motor coordination. A possibility is that the blocking impaired the perception of the visual stimuli that served as discriminatory cues. Given that the Acc itself is certainly not part of the visual system of birds (12), the effect might have been indirectly caused by an attentional impairment. A similar explanation has been offered for the deficits of Acc-lesioned rats performing a complex visual discrimination task (25).

Remarkably, Apo injections into the Acc did not have any effect on the same discriminatory performance of the pigeons, even at a high dose (Table 3). The Acc of birds is assumed to receive a significant dopaminergic input from the midbrain tegmentum, and Apo administered elsewhere (systemically or cerebrally) is known to elicit stereotypies and to act rewardingly in pigeons $(20,35)$. However, it is possible that the additional dopaminergic Acc stimulation due to Apo injection did not add significantly to the normal dopamine drive. Further conclusions about a dopamine involvement in avian Acc functioning may have to be postponed until antagonist, rather than agonist, substances have been tested. The attempt to block the Acc unspecifically with Lid was probably void because it was too short-acting an anaesthetic to be an effective blocker. We thus cannot assess what effect a general inactivation of the Acc might have on the perceptual performance of the pigeons. The method to try next in this respect is to use chronic Acc lesions. It might also be an occasion to pay regard to the considerable extent and the possible functional regionalization of the Acc in birds (cf. (23)).

Although other studies addressing the role of the Acc in perception are few (25), there is, as already mentioned, much evidence from experiments on rats that it is implicated in learning and memory competencies that include substantial perceptual components (1,29-31). A review indicates that, as already argued with respect to our own results, the impairments reported cannot be easily ascribed to simple motoric or motivational deficits. In humans, in any case, schizophrenia appears to be connected with a pathophysiology of the Acc (22) and, in turn, the illness is well known to include disturbed perceptions as a core symptom (5). An impaired perception of visual forms has been confirmed in schizophrenics using a quantitative version of Bender's visuo-motor test (6). Indeed, perceptual disturbances of a gestaltic nature have also been considered to underlie the delusional cognitions of such patients (4). The present results, suggesting that perceptual disturbances are connected with glutamatergic rather than dopaminergic Acc mechanisms, could be seen as agreeing with the newer glutamatergic hypothesis (7) rather than the older dopaminergic theory $(16,21)$ of schizophrenia. In any case, the pigeon might be a useful model (14) for investigating the alterations that underlie the delusions of schizophrenia.

\section{ACKNOWLEDGMENTS}

The research was supported by a grant to J. D. D. from the Deutsche Forschungsgemeinschaft, Bonn. While at Konstanz, P. A. G. was a recipient of a visiting fellowship from the Deutscher Akademischer Austauschdienst, Bonn. We thank L. Xia for assistance with the equipment, C. Lehr and I. Krug for assistance with the experiments, R. Leydel for help with the manuscript, and Professor J. Emmerton (Purdue) for comments and language improvements. We are also grateful to Dr. R. K. W. Schwarting (Düsseldorf) and Professor B. Rockstroh (Konstanz) for providing us with selected bibliography.

\section{REFERENCES}

1. Annett, L. M.; McGregor, A.; Robbins, T. W. The effects of ibotenic acid lesions of the nucleus accumbens on spatial learning and extinction in the rat. Behav. Brain Res. 31:231-242; 1989.
2. Carlezon, W. A.; Wiese, R. A. Rewarding actions of phencylidine and related drugs in nucleus accumbens shell and frontal cortex, J. Neurosci. 16:3112-3122; 1996. 
3. Carlsson, M.; Carlsson, A. Schizophrenia: A subcortical neurotransmitter imbalance syndrome? Schizophr. Bull., 16:425-432; 1990.

4. Conrad, K. Die beginnende Schizophrenie, Versuch einer Gestaltsanalyse des Wahnsinns [Incipient schizophrenia: an attempt at a gestaltic analysis of insanity]. Stuttgart: Thieme; 1966.

5. Costello, C. G., ed. Symptoms of schizophrenia. New York; Wiley; 1993.

6. Del Vecchio, S.; Gargiulo, P. A. Visual and motor function in schizophrenic patients. Acta Psiquiat. Psicol. Am. Lat., 38:317-322; 1992.

7. Deutsch, S. I.; Mastropaolo, J.; Schwartz, B. L.; Rosse, R. B.; Morihisa, J. M. A glutamatergic hypothesis of schizophrenia. Clin. Neuropharm. 12:1-13; 1989.

8. Dietl, M. M.; Palacios, J. M. Neurotransmitter receptors in the avian brain. I. Dopamine receptors. Brain Res. 439:354-359; 1988.

9. Emmerton, J. and Delius, J. D. Beyond sensation: Visual cognition in pigeons. In: Zeigler, P.; Bischof, H.-J., eds. Vision, brain and behavior in birds. Cambridge, MA: MIT Press; 1993:377-390.

10. Gargiulo, P. A. Thyreotropin releasing hormone injected into the nucleus accumbens septi selectively increases face grooming in rats. Brazil. J. Med. Biol. Res. 29:805-810; 1996.

11. Gray, J. A. Dopamine release in the nucleus accumbens: The perspective from aberrations of consciousness in schizophrenia. Neuropsychol., 33:1143-1153; 1995.

12. Güntürkün, $\mathrm{O}$. The functional organization of the avian visual system. In: Andrew, R. J., ed. Neural and behavioural plasticity: the use of the domestic chick as a model, Oxford, UK: Oxford University Press. 1991:92-105.

13. Hall, K.; Brauth, S. E.; Kitt, C. A. Retrograde transport of H3 GABA in the striatotegmental system of the pigeon. Brain Res. 310:157-163; 1984.

14. Henn, F. A.; McKinney, W. T. Animal models in psychiatry. In: Meltzar, H. Y. ed. Psychopharmacology: The third generation of progress, New York: Raven Press; 1987:687-695.

15. Hof, P. R.; Dietl, M. M.; Charnay, Y.; Martin, J. L.; Bouras, C.; Palacios, J. M.; Magistretti, P. J. Vasoactive intestinal peptide binding sites and fibers in the brain of the pigeon Columba livia: An autoradiographic and immunohistochemical study. J. Comp. Neurol. 305: 393-411; 1991.

16. Kahn, R. S.; Davis, K. L. New developments in dopamine and schizophrenia. In: Bloom, F. E.; Kupfer, D. J., eds. Psychopharmacology: The fourth generation of progress. New York: Raven Press; 1995: 1193-1203.

17. Karten, H. J.; Hodos, W. A. Stereotaxic atlas of the brain of the pigeon. Baltimore: Johns Hopkins Press; 1967.

18. Kitt, C. A. and Brauth, C. A. Telencephalic projections from midbrain and isthmal groups. II. The nigral complex. J. Comp. Neurol. 247:92$110 ; 1985$

19. Koob, G. F. Neural mechanisms of drug reinforcement. In: Kalivas, P. W.; Samson, H. H., eds. The neurobiology of drug and alcohol addiction. Ann. NY Acad. Sci. 654:171-191; 1992.

20. Lindenblatt, U.; Delius, J. D. Nucleus basalis prosencephali, a substrate of apomorphine-induced pecking in pigeons. Brain Res. 453: $1-8 ; 1988$
21. Matthysse, S. Antipsychotic drug actions: A clue to neuropathology of schizophrenia? Fed. Proc. 32:200-205; 1973.

22. Matthysse, S. Nucleus accumbens and schizophrenia. In: Chronister, R. B.; De France, J. F., eds. The neurobiology of the nucleus accumbens. Maine; Haer Institute, 1981, pp. 351-359.

23. Pennartz, C. M. A.; Groenewegen, H. J.; Lopes da Silva, F. H. The nucleus accumbens as complex of functionally distinct neuronal ensembles: An integration of behavioural, electrophysiological and anatomical data, Progr. Neurobiol. 42:719-761; 1994.

24. Perkins, M. N.; Stone, T. W.; Collins, J. F.; Curry, K. Phosphonate analogues of carboxylic acids as amino acid antagonists on rat cortical neurons, Neurosci. Lett. 23:333-336; 1981.

25. Reading, P. J.; Dunnett, S. B.; Robbins, T. W. Dissociable roles of the ventral, medial and lateral striatum on the acquisition and performance of a complex visual stimulus-response habit. Behav. Brain Res. 45: $147-161 ; 1991$

26. Reiner, A.; Davis, B. M.; Brecha, N. C.; Karten, H. J. The distribution of enkephalin-like immunoreactivity in the telencephalon of the adult and developing domestic chicken. J. Comp. Neurol. 228:245-262; 1984.

27. Robbins, T. W. Cognitive deficits in schizophrenia and Parkinson's disease: Neural basis and the role of dopamine. In: Willner, P.; Scheel-Kruger, J., eds. The mesolimbic dopamine system: from motivation to action. New York: Wiley; 1991:497-528.

28. Salamone, J. D. The involvement of nucleus accumbens dopamine in appetitive and aversive motivation, Behav. Brain Res. 61:117-133; 1994.

29. Schacter, G. B.; Yang, C. R.; Innis, N. K.; Mogenson, G. J. The role of the hippocampal-nucleus accumbens pathway in radial-arm maze performance. Brain Res. 494:339-449; 1989.

30. Scheel-Kruger, J.; Willner, P. The mesolimbic system: Principles of operation. In: Willner, P.; Scheel-Kruger, J. eds. The mesolimbic dopamine system: from motivation to action. New York: Wiley; 1991: $559-597$.

31. Seamans, J. K.; Phillips, A. G. Selective memory impairments produced by transient lidocaine-induced lesions of the nucleus accumbens in rats. Behav. Neurosci., 108:456-468; 1994.

32. Siemann, M.; Fersen, L. von, \& Delius, J. D. Kognition bei Tieren [Cognition in animals]. In: Irle, E.; Markowitsch, H. J., eds. Enzyklopädie der Psychologie, Vergleichende Psychobiologie. Göttingen: Hogrefe (in press).

33. Svenson, A.; Carlsson, M. L.; Carlsson, A. Crucial role of the accumbens nucleus in the neurotransmitter interactions regulating motor control in mice. J. Neural Transm. 101:127-128; 1995.

34. Veenman, C. L.; Wild, J. M.; Reiner, A. Organization of the avian "corticostriatal" projection system, a retrograde and anterograde pathway tracing study in pigeons. J. Comp. Neurol. 354:87-126; 1995.

35. Wynne, B.; Delius, J. D. Frontal forebrain lesions: Effects on the foraging and apomorphine pecking of pigeons. Physiol. Behav. 59: $757-762 ; 1996$.

36. Xia, L.; Delius, J. D.; Siemann, M. A multistimulus, portable and programmable conditioning panel for pigeons, Behav. Res. Methods Instrum. Comput. 28:49-54; 1996. 